УДК 069.9+001.32

ББК 79.24+72.6(2Poc)

DOI 10.31554/2222-9175-2020-40-133-139

С. А. Батурин

МЕМОРИААЬНЫЕ ВЫСТАВКИ В МУЗЕЕ БНЦ СО РАН: ОПЫТ СОЗААНИЯ И ПРОВЕАЕНИЯ

Анализируется опыт создания и проведения мемориальных выставок, посвященных ученым гуманитарного направления. Рассматривается сложившаяся практика организации мемориальных выставок в Музее БНЦ СО РАН. В хронологическом порядке перечислены наиболее значимые выставочные проекты, осуществленные музеем за последнее десятилетие.

Ключевые слова: выставочная деятельность, мемориальная выставка, экспонат, ученый, научное мероприятие.

\title{
S. A. Baturin
}

\section{MEMORIAL EXHIBITIONS AT THE MUSEUM OF BSC SB RAS: EXPERIENCE OF CREATION AND CARRYING OUT}

The article analyzes the experience of creating and conducting memorial exhibitions dedicated to humanitarian scholars. The current practice of organizing memorial exhibitions at the Museum of the BSC SB RAS is considered. The museum's most significant exhibition projects over the past decade are listed in chronological order.

Keywords: exhibition activity, memorial exhibition, exhibit, scientist, scientific event.

$\mathrm{B}$ ыставочная деятельность для музея является одним из важнейших средств популяризации историко-культурного наследия. Среди многих прочих разновидностей и типов выставок мемориальные выставки и деятельность, связанная с их организацией, связывают в первую очередь с деятельностью мемориальных музеев. Профиль мемориального музея определяется сферой деятельности, в которой прославила себя меморируемая личность. Наиболее многочисленны в РФ мемориальные литературные музеи, что определяется нашим особым отношением к литературе и к роли писателя как пророка и учителя. Представительные группы составляют мемориальные художественные, музыкальные и театральные, научнотехнические, военно-исторические, историко-революционные и др. исторические музеи [Российская музейная энциклопедия 2001].

Многие музеи, официально не являясь «мемориальными», имеют достаточно оснований вести комплектование фондов и организацию экспозиций и выставок, связанных с меморируемым лицом или событием. Мемориальные проекты на современном этапе имеют разнообразные направления музейной деятельности - культурно-образовательное, выставочное, посвящены созданию новых экспозиций и даже музеев, музеефикации историко-культурного наследия. Реализуются не только в пространстве мемориальных музеев, значительное распространение полу-

БАТУРИН Сергей Александрович - кандидат исторических наук, главный хранитель музейных предметов Музея Федерального государственного бюджетного учреждения науки «Бурятский научный центр СО РАН» (г. Улан-Удэ, Россия). E-mail: serba81@mail.ru. 
чили мемориальные проекты, создаваемые на площадках и на базе фондовых собраний (зачастую никогда ранее не выставлявшихся) краеведческих, художественных музеев, а также музеев-заповедников. В отдельную группу можно выделить партнерские проекты, авторы которых, привлекая различные структуры местного сообщества (профессиональные, конфессиональные, управленческие), смогли осуществить свою идею, сделать музей востребованным и значимым в регионе [Чувилова 2012: 23]. Ряд мемориальных выставочных проектов не только позволяют напомнить обществу о личности и событиях, связанных с ней, но и вводят в научный и музейный оборот новые объекты музейного показа - фотодокументы, рукописи, архивные материалы, документы личного происхождения.

В Музее БНЦ, который по своему профилю является комплексным, выставочная деятельность за годы работы приобрела свои специфические черты. Одним из приоритетных направлений выставочной деятельности музея является создание мемориальных выставок, посвященных памяти видных ученых. За последнее десятилетие (2009-2018 гг.) в музее было осуществлено более 130 выставочных проектов, из них 23 приходится на мемориальные, что составляет почти 18 \% общего числа проводившихся выставок. Большинство мемориальных выставок действовало в рамках научных мероприятий: конференции, круглые столы, семинары, ученые советы и т. д. Соответственно, инициатором и заказчиком становился научно-исследовательский институт. В этом случае выставочный проект осуществлялся совместно с инициативной группой ученых института. Ряд выставок создавались по инициативе музея в соответствии с планом выставочной работы. Сотрудники институтов в этом случае оказывали непосредственную консультативную помощь, а также предоставляли необходимый материал для создания выставки.

В отличие от сложившейся практики музеев Минкультуры, в Музее БНЦ СО РАН редко проводятся выставки, подготовленные сторонними организациями, однако при подготовке своих выставок в подавляющем большинстве случаев музей привлекает материалы партнеров - научных, образовательных организаций региона.

В зависимости от целей создания, а также от наличия выставочного материала выставки приобретают различный формат. В большинстве своем они носят плоскостной характер. То есть основными выставочными экспонатами являются документы: рукописные материалы, фотографии, репринты статей, копии научных докладов и т. д. Реже представлены личные вещи ученого, награды. Передвижные, плоскостные выставки монтируются на стенды и проходят рядом с местом проведения научного мероприятия. Как правило, такие выставки создаются на 6-8 плакатах на время проведения мероприятия. Мемориальные выставки с большим содержанием размещаются в выставочном модуле лабораторного корпуса научного центра на срок от 1 до 3 месяцев.

За длительный период сложилась практика делить выставки, посвященные памяти ученого, по двум направлениям - естественнонаучному и гуманитарному.

Мемориальные выставки ученых гуманитарного направления отличаются большим количеством архивного материла, рукописей статей, планов, отчетов. Для подготовки выставки сотрудниками музея проводилась работа с архивом Бурятского научного центра, личным архивным фондом Центра восточных рукописей и ксилографов ИМБТ СО РАН (ЦВРК ИМБТ СО РАН). Большой вклад в создание выставки вносили родственники, друзья, коллеги ученого, предоставляя личные материалы.

В 2009 г. совместно с Центром восточных рукописей и ксилографов ИМБТ СО РАН были организованы мемориальные выставки Алексея Ильича Уланова, Игнатия Дмитриевича Бураева и Гармажапа Лудуповича Санжиева. Материалы для 
них в основном были взяты из личного архивного фонда ЦВРК ИМБТ СО РАН. Экспонирование этих выставок также осуществлялось в помещениях ЦВРК. В целом выставки представляли собой экспонированный ряд фотографий и документов с общим поясняющим текстом. В качестве этикетажа выступали подписи к фотографиям (фото 1). Новым в работе музея стало то, что материал для выставки не только собирался и отбирался, но и проходил необходимую обработку. Так, например, 43 фотографии, которые де-

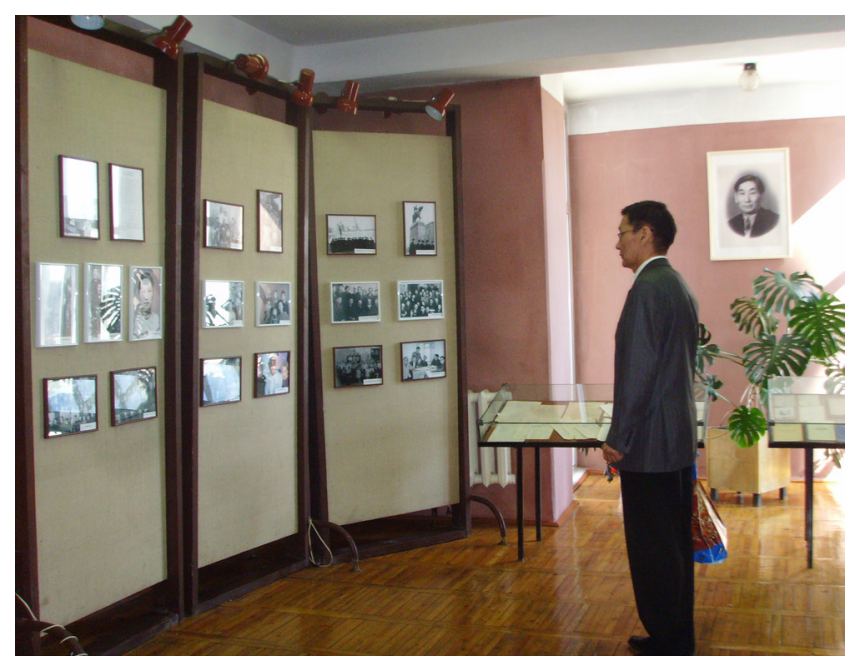

Фото 1. Выставка, посвященная А. И. Уланову монстрировались на выставке, посвященной А. И. Уланову, - это отсканированные копии, которые в большинстве своем прошли цифровую обработку и увеличение до необходимых размеров. Таким образом, Музей БНЦ СО РАН не только выявил и продемонстрировал на выставках исторический мемориальный материал, но и пополнил фонд цифровых копий подлинных документов.

В 2011 г. была организована выставка, посвященная 80-летию Александра Бадмаевича Соктоева. Она проводилась в рамках научного мероприятия и представляла собой фотогалерею с комментариями и подписями, размещенную в холле конференц-зала БНЦ СО РАН.

Сотрудниками музея в 2013 г. организована выставка к 100-летию со дня рождения талантливого ученого-филолога Михаила Петровича Хомонова. Открытие и проведение ее стало одним из мероприятий, посвященных памяти и научному наследию М. П. Хомонова. В общей сложности на выставке было продемонстрировано более 40 архивных фотографий, а также публикации, рукописи и личные вещи ученого.

Труды М. П. Хомонова являются не только достоянием фольклористической науки Бурятии, но и несомненным вкладом в общую мировую культуру. Они сохраняют свою актуальность и в наши дни, способствуя дальнейшему изучению духовного наследия бурятского народа. Основные направления научных исследований ученого - это бурятское эпосоведение, языкознание, монгольская и бурятская Гэсэриада и памятник древнемонгольской литературы «Сокровенное сказание монголов».

В честь 100-летия М. П. Хомонова Институт монголоведения, буддологии и тибетологии СО РАН провел ряд юбилейных мероприятий. Так, 25 апреля 2013 г. в присутствии сотрудников ИМБТ СО РАН, друзей и коллег, земляков и родственников ученого состоялось торжественное открытие мемориальной доски на доме, где он жил, по адресу: ул. Солнечная, 39. В этот же день в ЦВРК ИМБТ СО РАН открылась выставка, посвященная жизни и творчеству М. П. Хомонова. Организаторы ее - Музей и научная библиотека БНЦ СО РАН представили фотоматериалы и научные труды юбиляра [Бурчина 2013: 279].

В 2014 г. сотрудниками Музея БНЦ СО РАН совместно с учеными ИМБТ СО РАН была создана выставка, посвященная 100-летию со дня рождения Лазаря Ефи- 
мовича Элиасова. С именем Л. Е. Элиасова связана целая эпоха сибирской фольклористики, на протяжении почти трех десятилетий «он был признанным ее лидером и создателем сибирской фольклористической школы» [Матвеева 2014: 201].

Выставка проводилась в Центре восточных рукописей и ксилографов ИМБТ СО РАН и была дополнением к Всероссийской научной конференции «Традиционная культура Сибири: языки, миф, фольклор». На относительно небольшом пространстве в шести плакатах удалось рассказать о жизни и деятельности ученого. Экспозиция была дополнена публикациями как самого Л. Е. Элиасова, так и по тематике его исследований.

С конца 2013 г. Музей БНЦ СО РАН получил возможность создавать и демонстрировать стационарные выставки. В холле 1-го этажа главного корпуса БНЦ СО РАН был смонтирован современный выставочный модуль, где можно разместить не только плоскостной материал, но и музейные предметы, книги, архивные документы. В среднем на площади более 12 м² свободно размещаются около 120 фотографий, оцифрованные документы, иллюстрации и т. д. Современные технологии позволяют демонстрировать видеоролики и фотографии при помощи ЖК-телевизора. Выставки, в т. ч. и мемориальные, получили свое, ставшее уже постоянным, место демонстрации. Со временем сложилась практика открытия мемориальной выставки во время проведения научной конференции. Кроме того, продолжилась работа и над переносными временными выставками, преимущественно ориентированными на то пространство, где проходит научное мероприятие.

Выставка памяти Сергея Владимировича Данилова «Труды докажут, что мы жили» - одна из трех мемориальных выставок гуманитарного направления 2015 г., проводилась в рамках научно-практической конференции (фото 2).

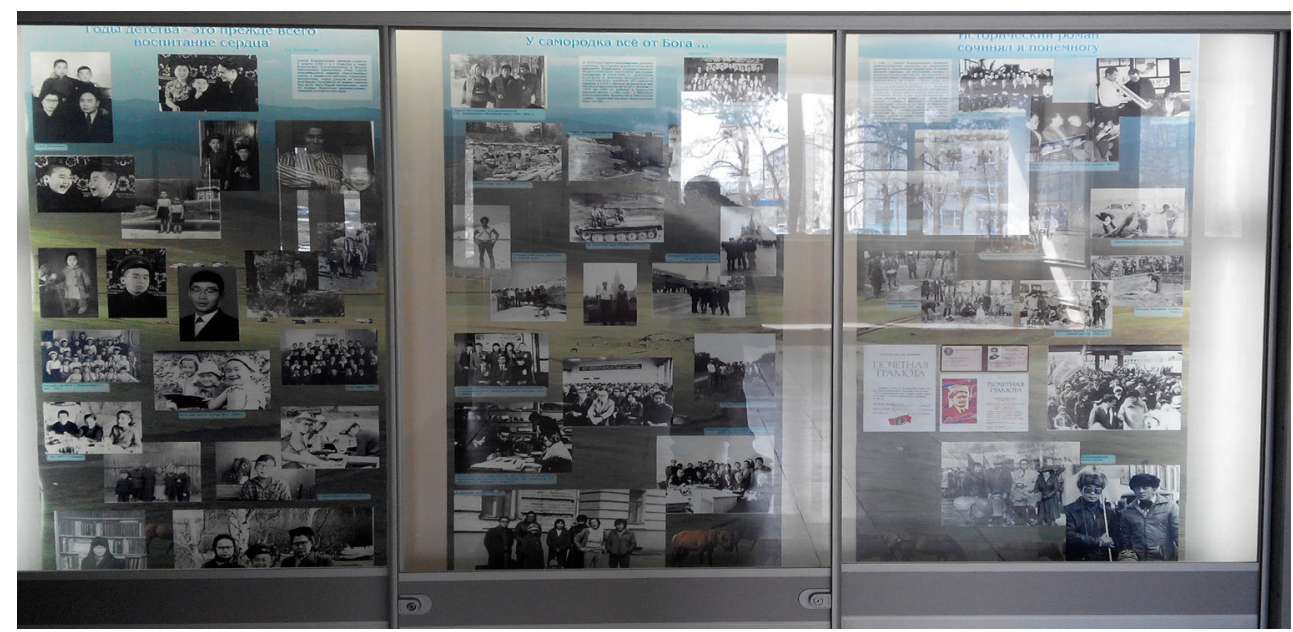

Фото 2. Выставка, посвященная С. В. Данилову

В том же году были проведены выставки памяти Цыбикжаба Бобоевича Цыдендамбаева - выдающегося ученого-бурятоведа, доктора филологических наук, одного из авторов двухтомной академической грамматики бурятского языка, а также выставка, посвященная 85-летию со дня рождения Лубсана Доржиевича Шагдарова - исследователя грамматического строя, стилистики, лексики, орфографии, синтаксиса бурятского языка. Первая выставка была создана в переносном формате, вторая - стационарная, размещенная в выставочном модуле. 
Интеграция музеев Сибири в социокультурное пространство: к 50-летию Музея БНЦ СО РАН

Переносная выставка, посвященная Ц. Б. Цыдендамбаеву, включала не только материалы, раскрывающие его научную деятельность, но и свидетельства фронтовой, общественной, личной жизни ученого, а также подборку трудов ученого, завершив, таким образом, целостный образ ученого-монголоведа (фото 3).

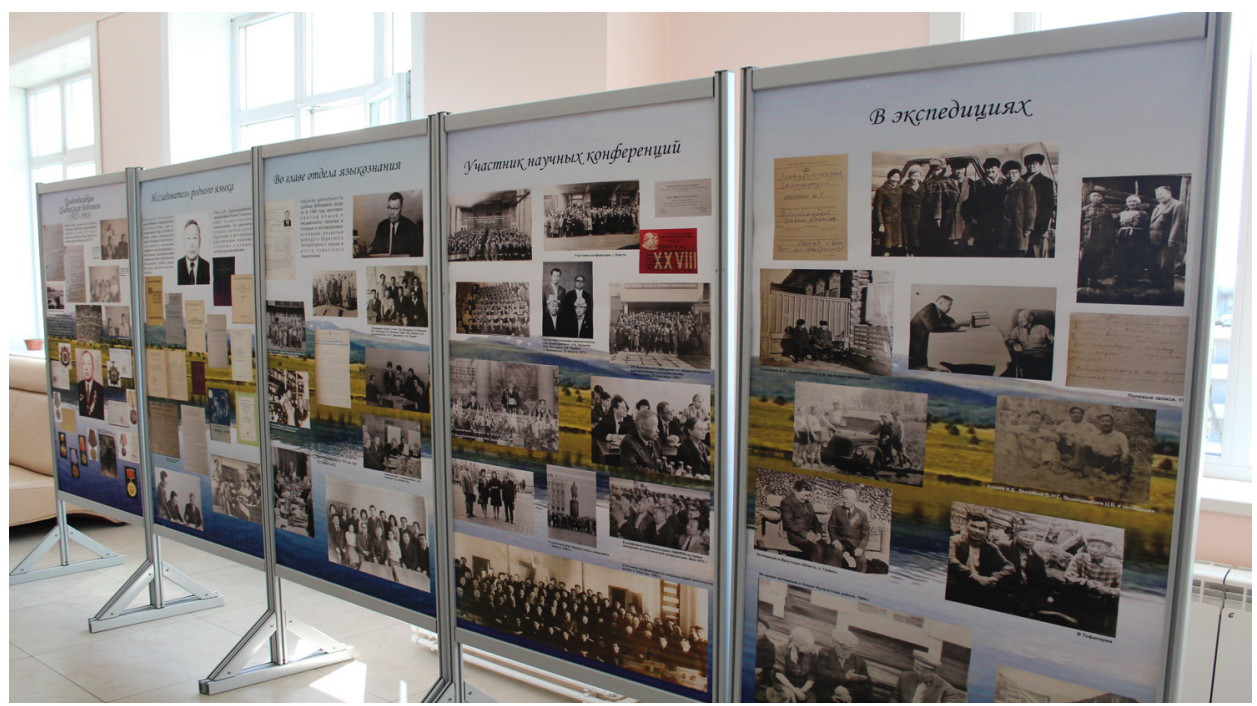

Фото 3. Выставка, посвященная Ц. Б. Цыдендамбаеву

Труды Ц. Б. Цыдендамбаева - ценный научный вклад, базовая методологическая основа для дальнейшего развития монголоведной науки. Образ Ц. Б. Цыдендамбаева, крупного ученого, целеустремленного, деятельного исследователя, талантливого организатора науки, принципиального, доброжелательного человека, честного гражданина, последовательного борца за сохранение и развитие языков, - нравственный вектор для творческой деятельности современных и будущих монголоведов [Биткеев 2015: 313].

Выставка, посвященная 85-летию со дня рождения Л. Д. Шагдарова, была построена в сложившейся тематической последовательности, учитывавшей количество демонстрируемого материала, а также использовавшей хронологический принцип. Повествование стало последовательным, начиная от детских лет ученого и заканчивая плакатом, рассказывающим о его учениках и последователях. Примерная схема расположения материала была такова: «Детские годы. Семья», «Учеба. Студенчество», «Научная деятельность», «Экспедиции», «Конференции», «Научные труды». Нужно сказать, что такая устоявшаяся тематика мемориальной выставки позже неоднократно изменялась, в зависимости от наполняемости темы и замысла автора выставки.

Выставка Александра Бадмаевича Соктоева в 2016 г. была размещена в выставочном модуле. Большой вклад в создание выставки внесли не только сотрудники ИМБТ СО РАН, но и родственники Александра Бадмаевича, предоставившие большое количество фотографического и архивного материала (более 300 единиц). Фотографии, не вошедшие в основную часть выставки, демонстрировались мультимедийными средствами.

В 2018 г. в рамках научных мероприятий, организованных ИМБТ СО РАН, прошла выставка известного ученого и организатора науки в Бурятии Василия Цыре- 
новича Найдакова, ученого-литературоведа, автора более 150 работ по вопросам литературы и театра, в т. ч. 17 личных и 10 коллективных монографий. Среди них наиболее значительными являются «Бурятская драматургия», «Современные писатели Бурятии», «Традиции и новаторство в бурятской советской литературе», «Там, где плещет Байкал», «Непроторенными путями», «Путь к роману», «Бурятская советская драматургия» (в соавторстве со С. С. Имехеловой) и др.

Глубина анализа и точность трактовки литературных явлений, постоянная ориентированность на актуальные направления исследования, проблемность и оригинальность, методологическая обоснованность и свежесть подходов характеризуют суть исследовательских направлений Василия Цыреновича Найдакова (из сопроводительного текста выставки).

При создании выставки использовались не только архивные материалы: документы, фотографии, публикации, но и личные вещи Василия Цыреновича, переданные на время проведения выставки родственниками ученого. Так, очень удачным экспонатом выставки, притягивавшим к себе большую долю внимания посетителей, стала бурятская национальная одежда, подаренная В. Ц. Найдакову по случаю юбилея. Во время сбора материала выставки автор неоднократно консультировался с сестрой Василия Цыреновича - Валентиной Цыреновной Найдаковой.

В июне 2019 г. была подготовлена и открыта выставка к 100-летию Ксении Максимовны Герасимовой. Мы смело можем констатировать, что обширные знания К. М. Герасимовой, огромный опыт настоящего исследователя определили основные направления научных интересов - это различные аспекты буддизма Центральной Азии: история, структура пантеона, синкретизм культовой системы, духовная культура; религия в истории и культуре Бурятии; религиозные обычаи бурят: история, современность, комплексные конкретно-социологические исследования религиозности сельского населения; буддийское искусство: эстетическая теория, иконометрический канон, региональные особенности художественного канона; тибетская медицина: особенности знаковой системы Атласа тибетской медицины (ATM); национальная культура бурят: структура, исторические формы, современные проблемы, традиционная народная культура; музейное дело: экспозиционные проекты, организация и проведение выставок [Жамсуева 2019: 249].

Выставка рассказывает о многогранности научных интересов ученого. В нее вошли фотографии, документы, рукописи из личного архива, хранящегося в ЦВРК ИМБТ СО РАН (фото 4).

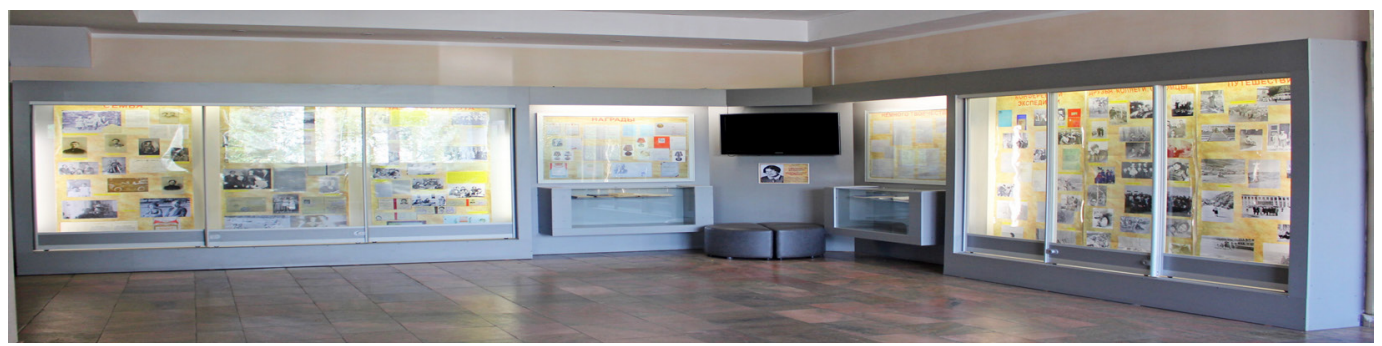

Фото 4. Выставка, посвященная К. М. Герасимовой

В выставочной деятельности Музея БНЦ СО РАН за его историю сложились определенные традиции и приоритеты. Начиная с 90-х гг. важными чертами выставочной программы музея стала демонстрация результатов исследований ученых Бурятии; мемориальное, событийное и коммеморативное направления - организация 


\section{Интеграция музеев Сибири в социокультурное пространство: к 50-летию Музея БНЦ СО РАН}

выставок, приуроченных к какому-либо событию в научной жизни. Мемориальные выставки стали не только средством почтить память выдающегося ученого, но и напомнить о нем нынешнему поколению молодых научных сотрудников, воспитать в них гордость за отечественную науку.

\section{Аитература}

Биткеев П. Ц. Достойный вклад в монголоведную науку (к 100-летию Ц. Б. Цыдендамбаева) / П. Ц. Биткеев // Вестник Бурятского научного центра СО РАН. - 2015. - № 2(18). C. $308-313$.

Бурчина Д. А. Юбилей М. П. Хомонова (1913-1995) / Д. А. Бурчина // Вестник Бурятского научного центра СО РАН. - 2013. - № 2(10). - С. 279-281.

Жамсуева Д. С. Яркий след в буддологической науке. К столетию К. М. Герасимовой (22.05.1919-17.06.2011) / Д. С. Жамсуева // Вестник Бурятского научного центра СО РАН. 2019. - № 2(34). - С. 246-251.

Матвеева Р. П. Л. Е. Элиасов и вопросы регионального исследования фольклора Сибири / Р. П. Матвеева // Вестник Бурятского научного центра СО РАН. - 2014. - № 2(14). С. 201-208.

Российская музейная энциклопедия: в 2 т. Т. 1. - М.: Прогресс; Рипол Классик, 2001. 416 с.: ил.

Чувилова И. В. Мемориальные музеи и проекты в современном социокультурном пространстве / И. В. Чувилова // Молодежь и социум. - 2012. - Спецвып. - С. 19-26.

\section{References}

Bitkeev P. C. Dostojnyj vklad v mongolovednuyu nauku (k 100-letiyu C. B. Cydendambaeva) / P. C. Bitkeev // Vestnik Buryatskogo nauchnogo centra SO RAN. - 2015. - № 2(18). S. 308-313.

Burchina D. A. Yubilej M. P. Homonova (1913-1995) / D. A. Burchina // Vestnik Buryatskogo nauchnogo centra SO RAN. - 2013. - № 2(10). - S. 279-281.

Zhamsueva D. S. Yarkij sled v buddologicheskoj nauke. K stoletiyu K. M. Gerasimovoj (22.05.1919-17.06.2011) / D. S. Zhamsueva // Vestnik Buryatskogo nauchnogo centra SO RAN. - 2019. - № 2(34). - S. 246-251.

Matveeva R. P. L. E. Eliasov i voprosy regional'nogo issledovaniya fol'klora Sibiri / R. P. Matveeva // Vestnik Buryatskogo nauchnogo centra SO RAN. - 2014. - № 2(14). - S. 201-208.

Rossijskaya muzejnaya enciklopediya: v 2 t. T. 1. - M.: Progress; Ripol Klassik, 2001. 416 s.: il.

Chuvilova I. $V$. Memorial'nye muzei i proekty v sovremennom sociokul'turnom prostranstve / I. V. Chuvilova // Molodezh' i socium. - 2012. - Specvyp. - S. 19-26. 